\title{
PARKING SEARCH OPTIMIZATION IN URBAN AREA
}

\author{
Maric, M. ${ }^{* * * *}$; Gracanin, D. ${ }^{* * * \#}$; Zogovic, N. ; Ruskic, N. ${ }^{* *} \&$ Ivanovic, B. ${ }^{* * *}$ \\ *University of Belgrade, Institute Mihailo Pupin, Volgina 15, 11000 Belgrade, Serbia \\ ${ }^{* *}$ University of Novi Sad, Faculty of Technical Sciences, Trg Dositeja Obradovića 6, 21000 Novi Sad, \\ Serbia \\ *** University of Montenegro, Faculty of Civil Engineering, Džordža Vašingtona bb, 81110 Podgorica, \\ Montenegro \\ E-Mail: milovan.maric@pupin.rs,gracanin@uns.ac.rs,nikola.zogovic@pupin.rs,nruskic@uns.ac.rs, \\ biljana.ivanovic@ viaproject.me ("Corresponding author)
}

\begin{abstract}
This study is a first step towards solving the parking search time optimization problem in urban area. By using adaptive multi-criteria optimisation model with system feedback for simulation of parking choice behaviour and drivers' preferences, presented by adequate utility function, we shown on real case that parking search time can by reduced by $70 \%$. We use publicly available demographic study as input data and Rockwell Automation Arena ${ }^{\circledR} 14$ software for processing and modelling. Various categories of data were evaluated based on results from 2,057 interviews with parking users. Our comparison of two models, everyday driver behaviour model and adaptive experimental optimisation model, shows a great potential in reducing parking search time. The analysed results show that search time decreases with information availability about three main criteria: acceptable walking distance, price and driving time.

(Received in February 2016, accepted in December 2016. This paper was with the authors 1 month for 2 revisions.)
\end{abstract}

Key Words: Optimisation, Open Data, Parking Prediction, Parking Search Time, Driver Utility

\section{INTRODUCTION}

Parking problem becomes one of major issues in fast growing cities like Novi Sad. Based on the transport demand forecast for 2009, it is estimated that in 2029, the number of cars will increase in Novi Sad by $64 \%$ compared to the current level, which corresponds to $2.5 \%$ annual growth. The city inhabitant mobility is also expected to increase, with 3 trips per day estimated for the end of the forecast period. In addition, Novi Sad has the largest visitor growth in Serbia, over $14 \%$ comparing with the last year and research conducted in 2004 showed that average demand for parking were about 10000 vehicle/day. With only 1500 onstreet and 150 off-street parking spots, $40 \%$ of drivers were forced to use no regulated parking places, leading to increased danger to other traffic participants and significant loss in city incomes.

Also, parking search time can lead to serious congestion issues. Based on review of 16 mostly American and European studies of cruising conducted between 1927 and 2001, Shoup [1] concludes that cars searching for free parking spot contribute to over $8 \%$ of total traffic. Also some studies showed that over $30 \%$ of vehicles in large cities downtown areas are cruising for a parking spot and that it takes an average of 7.8 minutes to find one. In addition, $60 \%$ of drivers have abandoned their search for a spot at least once and $25 \%$ of them have gotten into argument with another driver [2]. This issue is also supported by the fact that the average car is parked at home for about $80 \%$ of the time, parked elsewhere for about $16.5 \%$ of the time, and only actually used for the remaining 3.5\% [3]. Next to the directly resulted problem, congestion, air pollution, noise, more frequent accidents and infrastructure costs are the following issues. Parking infrastructure in most cases is located in central urban areas where land value is the highest. For example, in Novi Sad it is planned to construct the closed 
public garage at the lot area of around $2100 \mathrm{~m}^{2}$. By the actual land value the city must calculate income loss of $\sim 23$ mil. $€$ only for lot area (compared to the amount that the city could get at a public auction).

Even many studies have identified benefits of forecasting parking availability, there are only a few cases in which this topic is faced. In the last few years, some smart parking solutions that address the longstanding parking challenges have been developed [4].

Our initial motivation is to check parking search prediction possibilities in cities in Serbia. Since Serbia, as potential candidate for EU membership will be obligate to accept Acquis Chapter 27 (environmental issues), air pollution and other traffic related issues will be of main interest.

This paper describes the first phase of the current on-going research and should be the basis for future steps in solving parking search problem. The final objective is to develop an effective methodology for real-time parking utility forecasting including off-street (closed parking lots and garages with access, time limit, pricing restrictions) and on-street parking (side-street parking spots with time limit and pricing restrictions). In our case free parking spots in housing estates are not considered. All gathered information regarding local parking conditions is simulated in changed circumstances (real-case behaviour and situation with parking zone information broadcasted to the driver).

Our analysis is focused on systems and studies that support the search for parking spaces in urban areas. We give attention to parking garages or restrictive parking spots but also to new on-street solutions with online information system for informing drivers. It is shown that urban feedback has significant influence on sustainable traffic development [5]. Solutions of this type are the growing trend in Serbia. We categorize gathered information based on the nature of data source.

\section{RELATED WORK}

Parking problem is widely recognized issue but with low number of proposals with high TRL (Technology readiness levels). Current studies are mostly focused on identifying parking problem causes. More recently, with the development of mobile technologies, a few technical solutions have addressed this topic.

Assumptions based on small-scale measurements: There are numerous studies that only cover small geographical area and short-term vehicle counting. These approaches are mostly based on personal perceptions and limited data sources [6]. In our area of interested (e.g. city of Novi Sad) example of this approach is the Nostram traffic study [7] that for parking demand takes only the ratio of the number of registered vehicles and the number of available parking spaces. Vehicle tracks related to work, shopping, recreation, visits and other are only predictions. The same study performed small-scale measurement but only on selected number of cross-roads. In both cases, the lack of wide geographical surfaces and long term measurement leads to poor image of traffic complexity in urban area.

Demographic surveys: In the past demographic survey, as very important source for analytic data, was the only source of traffic related data. Recently cities in Serbia (e.g. Novi Sad) started implementing traffic counting systems in urban area but this solution is mainly limited to only few main streets. Also, some off-street parking garages made information about free parking spots available over the Internet. Never the less, demographic survey [8] still provides much wider scope of information such as: existing parking capacity (including parking lots outside official parking zones and closed parking lots), turnover rate (see Fig. 1), etc. 


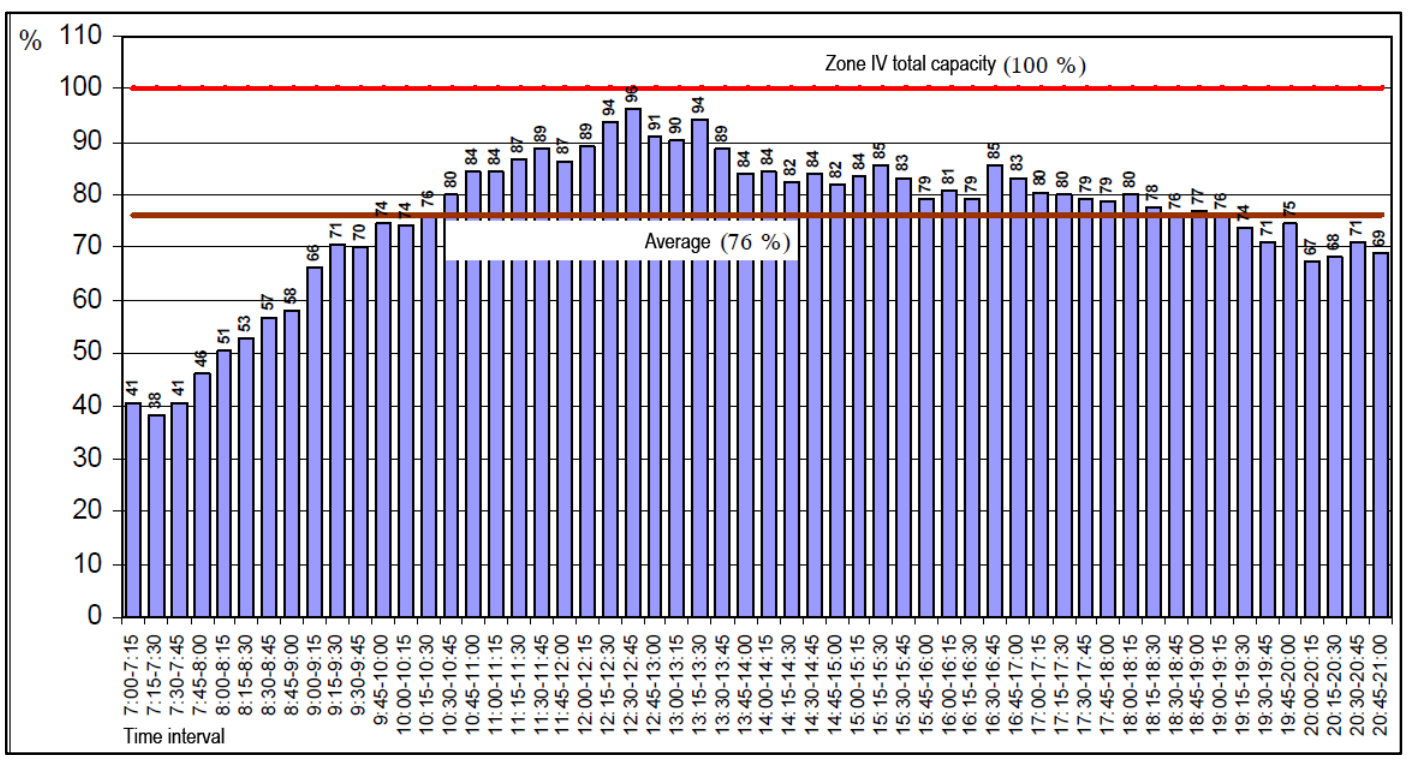

Figure 1: Zone IV parking spot occupancy counted during two days in 07:00 h-21:00 h time interval.

Smart-phone based systems: Smart-phone based systems [9] are an approach for informing drivers about available parking spots and guiding them to alternate car parks [10]. Information can be passed to other drivers by manually marking parking spot free/used via mobile app [11, 12] or automatically by some mobile sensing system [13]. Systems based on community involvement [14] and user data is currently the most frequent approach which also represents the most significant disadvantage, there is just too many of them. Numerous crowdsource systems led to widely decentralized information sources.

Systems based on publicly available data: The most of the future researches will increasingly rely on smart-city and open-data projects for solving this type of urban are problem. Some of the cities that have implemented open-data systems are Amsterdam, Barcelona, Berlin, Copenhagen, London, Paris, Stockholm and Vienna. They all have a municipality website and Open Data portal. At first look it may seem that parking lot status is information of local or regional interest, but it is not so. For example, the number of tourists in 2016 in city of Novi Sad was over 170 000, which represents more than $50 \%$ of the number of inhabitants. Intelligent transportation system (ITS) deployment in various cities of Europe can provide real-time parking information, such as location, capacity, current availability and significantly improving the decision making process [15]. In Novi Sad and Belgrade there is web-based information about some parking facilities (http://parkingservis.co.rs/gde-mogu-da-parkiram/) but still without convenient interaction with drivers.

Sensors based systems: Last year in Serbia represented the birth of sensor based parking systems. Two, independent, projects have presented their solutions. System installed in Belgrade in cooperation of Belgrade parking service and City of Belgrade installed 1000 Nedap [16] sensors on parking lots in three streets in Vracar municipality. Sensors are sending in $30 \mathrm{~s}$ intervals information about free spots to 40 info displays placed in surrounding streets. In this phase Web based informing is not provided.

Another project, also presented in 2016, in city Novi Sad is, for now, just in a pilot phase that includes a few parking sensors and supporting software. Unlike Belgrade solution, this system is completely developed on Faculty of Technical Science, University Novi Sad and presents the first domestic solution. In both cases two types of detection are used so a level of redundancy is built into the system.

Collecting real-time information about parking-lot status using sensors installed at every individual parking spot is not a new approach and we can identify few examples in other world cities. San Francisco founded pilot project in 2011 that covered 7000 m long parking 
area with individual sensors [17]. The city of Santander, in 2013, also started a similar project aiming to design a platform composed of sensors (375 in first phase) and screens to provide free parking information to the citizens [18].

As precise this information from parking sensor is, it comes with a significant price. Official data shows that, for example, in city of Belgrade there is 25000 on-street parking spots and, in San Francisco over 160000 on-street parking spots, only in the city area. Having that in mind and some assessment of the cost of $\sim 0.9 €$ per day for operation and maintenance of each sensor, it is doubtful that placing dedicated sensors could be likely solution for most of the cities.

Next to the sensors embedded at parking spots there are also other approaches dealing with parking occupancy monitoring. A notable example is ParkNet project. It uses on vehicle mounted passenger-side-facing ultrasonic rangefinder to observe on-street parking occupancy from a moving vehicle [19]. Also, street monitoring cameras and image processing [20] is potential data source. This approach is considered in Serbia where we have over 13 cities with 58 street speed and significantly more surveillance cameras. Information for parking occupancy can be also obtained by using images from the plains or drones [21].

\section{METHODOLOGY}

Based on presented related works in this field it can be noticed that there is still no longstanding, globally applied solution. Based on using available open data regarding particular parking area, e.g. city centre of Novi Sad, our approach is oriented practically. The most of currently public available parking information is still incomplete but as the other data become open and available parking search will be more and more efficient.

The dataset we introduce in this paper is based on publicly available data and data gathered by demographic survey [8] conducted by Faculty of Technical Science, University of Novi Sad that aimed to analyse parking occupancy and demand in urban area of the city of Novi Sad (Table I). Since the drivers' parking behaviour is influenced by a whole range of different factors, such as availability of parking spaces, walking time, cost and comfort we included in our parking management matrix public data such as:

- free parking space and cost information in off-street lots with real-time available data,

- parking on-street zones data with cost information,

- on-street parking spot availability statistics gathered by [8],

- increase in the volume of traffic events such as time of day and location.

This matrix summarizes how occupancy and drivers' utility are used to suggest the most appropriate parking lot.

City policy is increasingly relying on these factors for creating its parking policy. Higher pricing, time restrictions or parking spots reservations are just some examples of management techniques.

Table I: Model data sources.

\begin{tabular}{|c|l|l|}
\hline No. & \multicolumn{1}{|c|}{ Data } & \multicolumn{1}{|c|}{ Data source } \\
\hline 1. & Traffic situation & $\begin{array}{l}\text { Automatic side-street counters } \\
\text { http://www.mapanovisad.rs/mapserver2015/nsmaps/ }\end{array}$ \\
\hline 2. & Parking availability & $\begin{array}{l}\text { http://parking-servis.co.rs/gde-mogu-da-parkiram/ } \\
\text { Demographic survey [8] }\end{array}$ \\
\hline 3. & Weather data & Openweather API: https://openweathermap.org/api \\
\hline 4. & Weekday, time of the day & Universal Time (UCT) Server \\
\hline
\end{tabular}

Our model uses spatial and non-spatial input data. For spatial input data we have chosen central business district of the city of Novi Sad (see Fig. 2, left), with parking places and road 
networks, for this research, mapped in 6 zones (see Fig. 2, right). Parking instructions from a driver consists of the current car location (origin) and location of destination. The boundaries of zones are entry/exit spots where drivers can enter or leave the network of the study area. Parking choice model can be described according to a utility/disutility function:

$$
U_{i} \downarrow=U_{i} \downarrow \text { cost }+U_{i} \downarrow \text { travelTime }+U_{i} \downarrow \text { walkTime }+\ldots+\epsilon \downarrow U_{i},
$$

where $i$ is index of the parking zone.

Utility function can quantify drivers' satisfaction with parking and reaching the destination from the origin in $t$ minutes as $U(t)$. If parking spot has some type of sensor monitoring system or it is closed garage, calculating the utility is simple task of identifying the nearest open spot to the destination location. But, as we presented in our area this kind of information is very limited, so the parking occupancy cannot be known with absolute certainty.
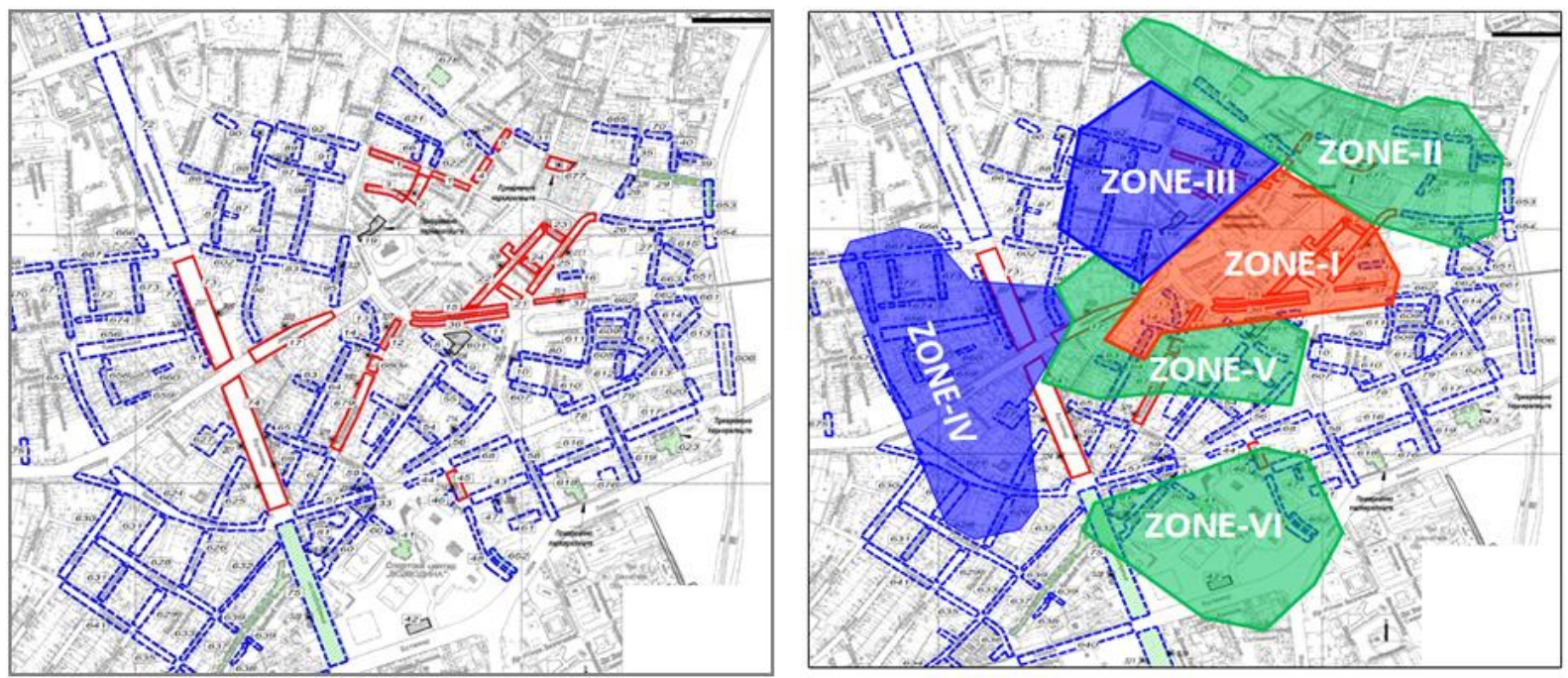

Figure 2: Mapping of existing parking spots in the city of Novi Sad.

Drivers' trip motives (going home, private business, shopping, business, tourism, etc.) together with destination are also recorded and taken into consideration. In a taken study one of the asked questions was the cause (reason) for arriving at the monitored location. The analysis shows that one of the dominant purposes for parking search is "shopping ", about $34 \%$ interviewed drivers (see Fig. 3). On the second place is "business" with participation of $32 \%$ followed by a "private business", $10.1 \%$ and "going home" participates with $8.6 \%$ in the overall response.

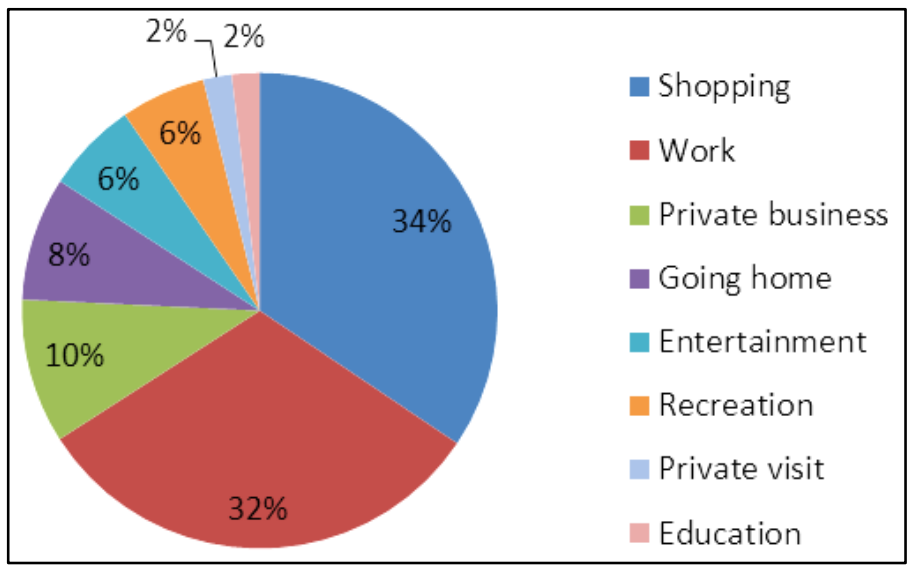

Figure 3: Parking search motives. 
Our model describes adaptive multi-criteria optimisation approach using (a) destination choice, (b) parking type choice (closed or on-street), (c) selection of parking facility (if b choice is closed parking) and (d) parking-search route choice. In the case of restricted parking, driver choses route to the closest parking facility with available spots. In the case of on-street parking, driver choses available route based on adequate utility preference.

Utility function aims to maximize the convenience and minimize parking costs. Based on [22] we describe utility function as:

$$
\begin{gathered}
\max U_{i}=w_{i} \log \frac{x_{m}}{x_{i}}-k_{s} \frac{s_{i}}{s_{\max }}-k_{p} \frac{p_{i}}{p_{\max }}, \\
\text { s.t. } x_{i}<x_{m}, p_{i}<p_{\max }, s_{i}<s_{\max }
\end{gathered}
$$

where:

$w_{i} \log \frac{x_{m}}{x_{i}}$ is walking distance convenience if user selects $i^{\text {th }}$ parking lot, $w_{i}$ is a coefficient that describes drivers' willingness to walk, $x_{m}$ is maximum accepted distance, $x_{i}$ is $i^{\text {th }}$ parking lot distance,

$k_{p} \frac{p_{i}}{p_{\max }}$ is relative cost for $i^{\text {th }}$ parking lot, $k_{p}$ is a coefficient that describes drivers' willingness to pay the parking fee, $p_{i}$ is $i^{\text {th }}$ parking lot fee, $p_{\max }$ is a maximum accepted parking fee,

$k_{s} \frac{s_{\max }}{s_{i}}$ is travel time convenience if user selects $i^{\text {th }}$ parking lot, $k_{s}$ is a coefficient that describes drivers' willingness to search parking lot, $s_{\max }$ is maximum accepted search time, $s_{i}$ is driving time to the $i^{\text {th }}$ parking lot.

In real case research, conducted in Novi Sad [8], we show that user parking search motives and budget limits have direct influence on parking price, walking and search time tolerance. We use survey results (the key parking criteria, parking use frequency, price and walking time limits) to determine $w_{i}, k_{p}$ and $k_{s}$ (see Figs. 4 and 5). To determine drivers (parking user) category we interviewed 2057 parking users. For interviews pre-prepared questionnaires, given by Table II, were used.

\begin{tabular}{|c|c|c|c|c|c|c|}
\hline 1 & Parking ticket type & e? a) daily ticket & b) monthly ticket & c) year ticket & \multicolumn{2}{|c|}{ d) special ticket } \\
\hline 2 & \multicolumn{6}{|c|}{ Number of passengers in vehicle? } \\
\hline 3 & \multicolumn{6}{|c|}{ Motive for parking search (trip motive)? } \\
\hline & a) travel to work & \multicolumn{3}{|c|}{ Are you always traveling to work by private vehicle? } & a) yes & b) no \\
\hline & b) going home & \multirow{3}{*}{\multicolumn{3}{|c|}{ How often you are coming to this parking zone? }} & a) daily & \\
\hline & c) shopping & & & & b) weekly & \\
\hline & d) other & & & & c) monthly & \\
\hline 4 & \multicolumn{2}{|c|}{ Final destination address? } & & & & \\
\hline 5 & \multicolumn{2}{|c|}{ Expected walking time? } & & & & \\
\hline 6 & \multicolumn{2}{|c|}{ Accepted parking price for you? } & & & & \\
\hline 7 & \multicolumn{3}{|c|}{\begin{tabular}{|l|l|} 
The most important parking criteria for you? & a) free spot \\
\end{tabular}} & b) walking time & c) price & d) other \\
\hline 8 & \multicolumn{2}{|c|}{ Would you use parking garage? } & a) always & b) sometimes & \multicolumn{2}{|l|}{ c) never } \\
\hline 9 & \multicolumn{2}{|c|}{ Your suggestions for parking service } & & & & \\
\hline
\end{tabular}

Table II: Questionnaire format.

As research showed the price was identified as main factor for parking lot decision and maximum drivers' convenience. 

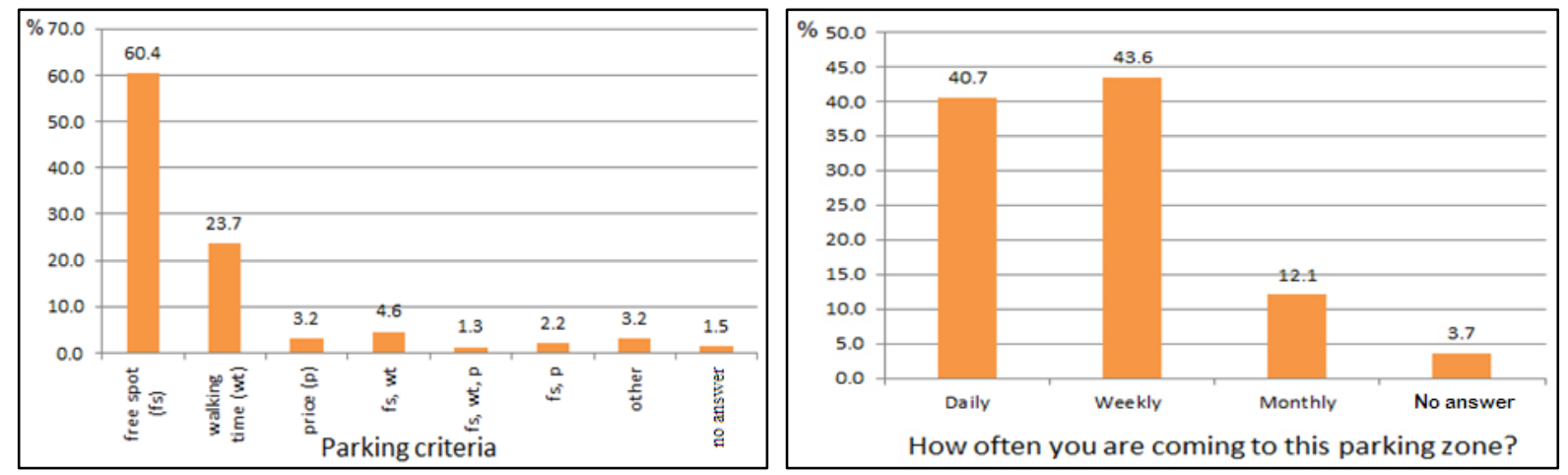

Figure 4: The most important parking criteria and parking usage intensity.
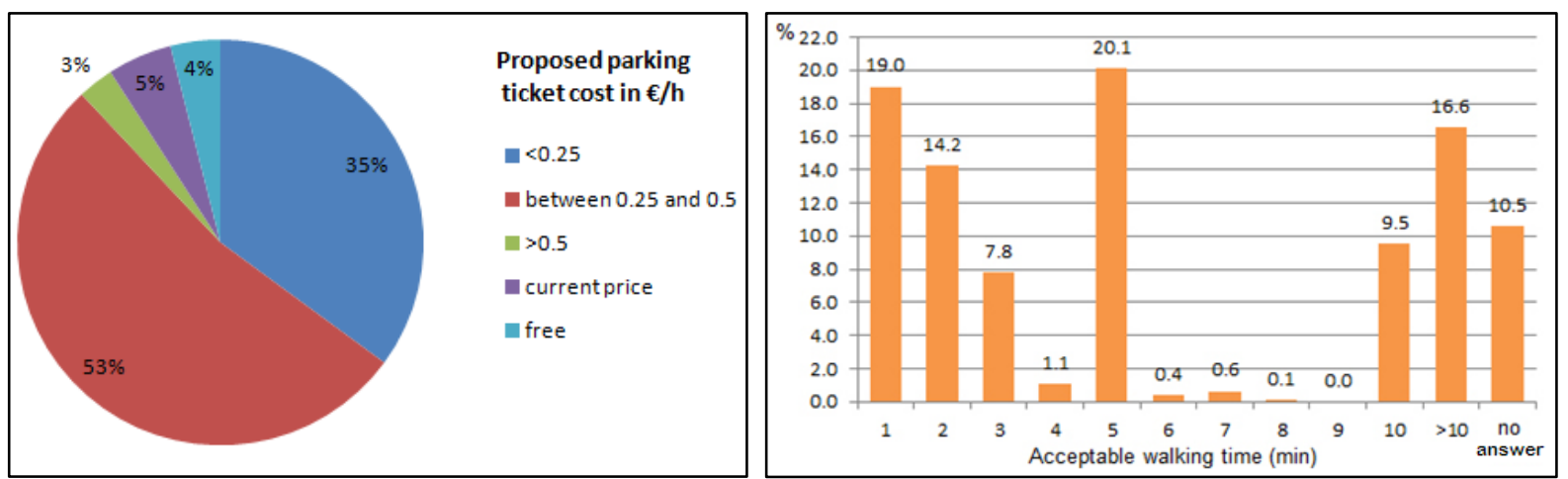

Figure 5: Price and walking time limits for parking service.

\section{PREDICTION OF THE PARKING SITUATION SIMULATION}

In this paper we tend to predict the probability of a parking lot being available at the estimated time that the car will arrive there taking into account all available information. We assume that this information can be broadcasted to vehicles. We have chosen six parking zones, which acts like individual parking lots. In our situation all parking spots are close enough so the driving cost (time, fuel, etc.) is practically the same regardless of which parking the driver decides to go. Parking lot usage should be balanced enough to minimize traffic congestion and maximize driver satisfaction.

The system is determined by the following assumptions:

1) The arrival process for the set of vehicles $V=\left\{v_{1}, v_{2}, v_{3}, \ldots v_{m},\right\}, m=0,1,2, \ldots$ is Poisson with rate $\lambda, P(N=n)=\frac{\lambda^{n}}{n !} e^{-\lambda}, n=0,1,2, \ldots$

2) Parking session duration is random with an exponential distribution of 30 minutes mean.

3) A vehicle will be assigned to the parking zones, $Z=\left\{z_{1}, z_{2}, z_{3}, \ldots z_{i},\right\}, i=0,1,2, \ldots$ with capacity $C_{i}$ and the number of free spaces $N_{i}(t)$ for $i^{\text {th }}$ zone based on probability:

$$
p_{i}(t)=\frac{N_{i}(t)}{\sum_{i=1}^{l} N_{i}(t)}, l-\text { max. number of parking zones }
$$

With this rule we can reflect many other utility factors such as cost, walking time, etc.

4) In the first scenario the utility function is the same for all parking lots.

$5)$ In the second scenario the utility function weights $\left(w_{i}, k_{s}, k_{p}\right)$ obtained from demographic survey are used in decision making process.

We have a network of six parking zones [8] shown in Fig. 2. For simulation purposes we assume that capacities in available parking zones are: $C_{1}=40, C_{2}=20, C_{3}=40, C_{4}=35$, $C_{5}=30$ and $C_{6}=30$. Based on [8] we have counted near 1000 vehicles/hour arrive/exit to/from 
this area. For simulation purposes the vehicles enter in the area according to a Poisson process with mean of $6 \mathrm{~s}$. We assume that all vehicles enter from the same main roads and average parking session duration is $30 \mathrm{~min}$. Simulation replication length is $2 \mathrm{~h}$.

In the first scenario we simulated driver behaviour in real conditions [7]. Following assumptions are considered: a) driver initially does not have information about parking lots status, b) driver selects the parking lot based on initial trip motive and c) if selected parking lot is occupied driver moves to the next one. Travel time from initial location is the same for all drivers and it takes 2 minutes. In the case when chosen parking zone is occupied time to move to the next one is 1 minute. The model further assumes that drivers are searching for a free parking spot without giving up.

We validate simulation model using real case data and confirm the results presented by previous researches. After period of 2 hours, $8.5 \%$ of total time was spent on parking search (comparing with [1]). Also, 585 vehicles, from the total number of 1200, were able to find free parking spot which leads to the conclusion that more than $33.5 \%$ of drivers were forced to use no regulated parking places or give up the parking search (Novi Sad demographic survey, 2004). Also, it is important to mention that after 2 hours 420 vehicles had remained on road searching for free parking spot leading to congestion and air pollution problem.

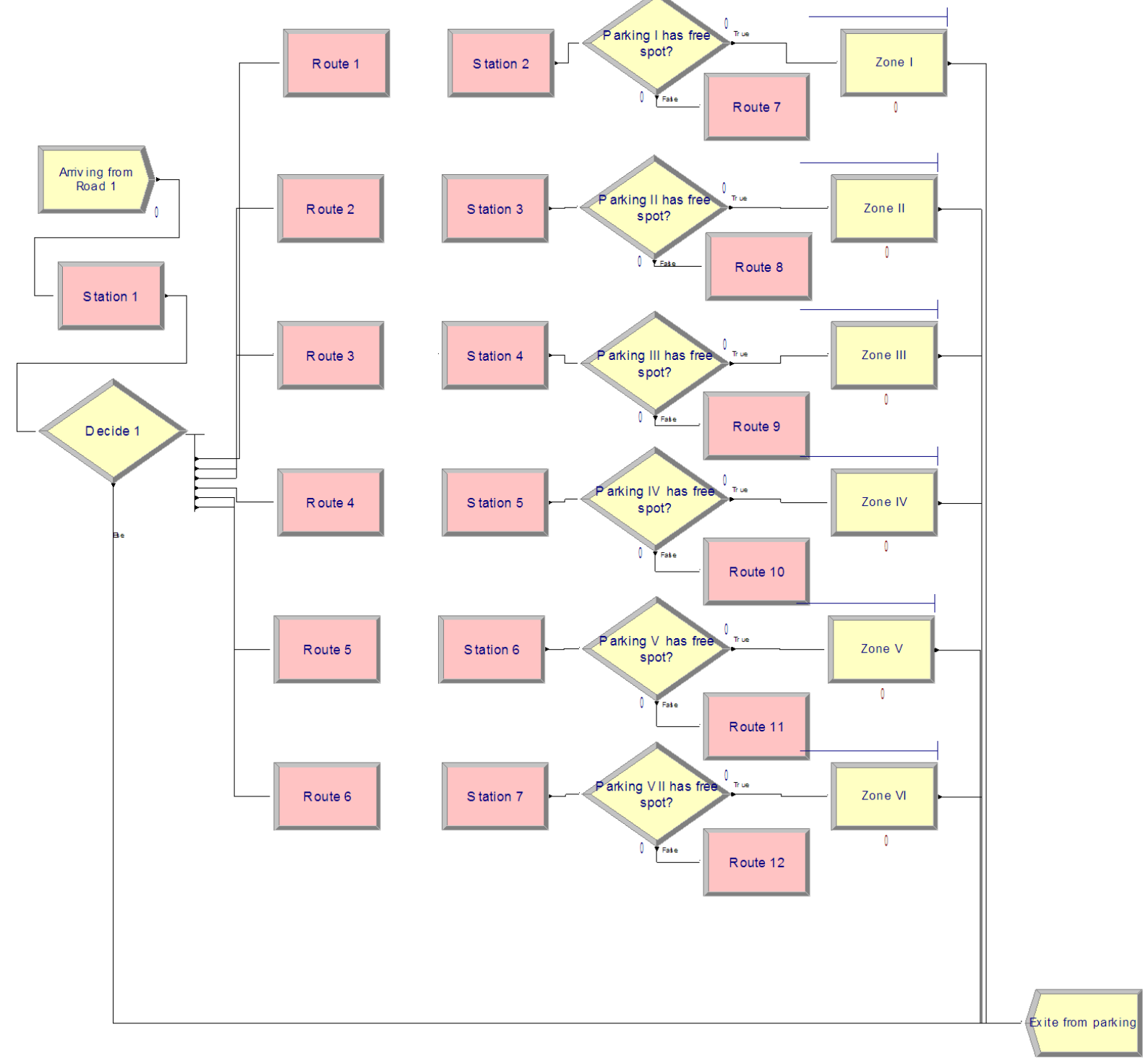

Figure 6: Arena simulation model showing the parking search process real-life behaviour. 
In the second scenario (see Fig. 7) we simulated experimental parking search model. Following assumptions are considered: a) driver initially has information about parking zones status, b) if all parking zones are full, driver does not enter this urban area, c) driver selects the parking based on the probability of free spots, d) based on the results from [7] we assumed that $41 \%$ of drivers will initially choose parking Zone I - minimizing walking time, e) Zone I is chosen for initial parking location based of analysed trip motives [7] and e) if selected parking lot is occupied, driver rechecks all zones availability.

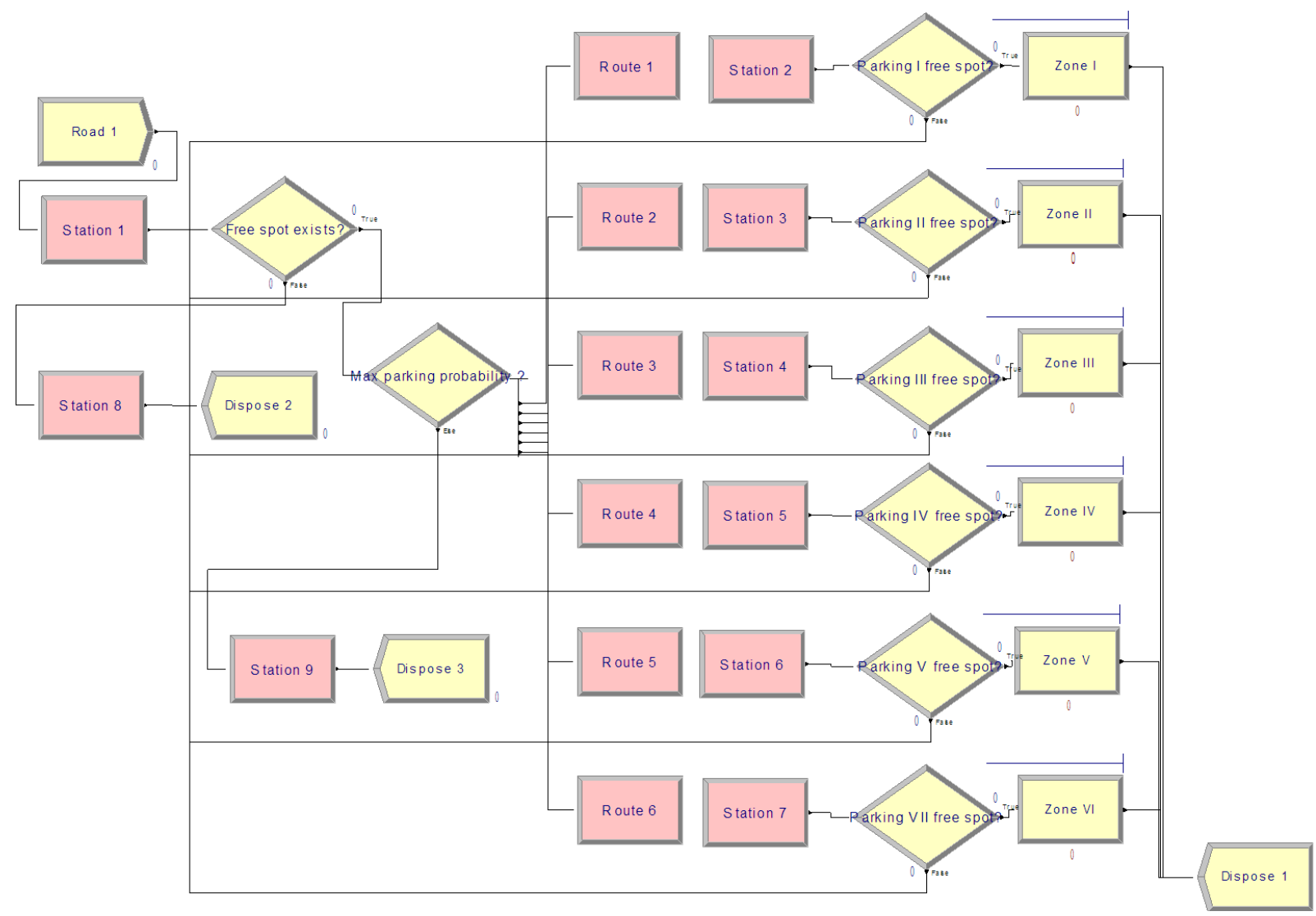

Figure 7: Arena simulation model showing the experimental parking search process.

Also, we have used adaptive multi-criteria optimisation model (see Fig. 8) for simulation of parking choice behaviour. Through demographic survey we have identified and included in the utility function (see Eq. (2)), the main three criteria that influence drivers' adaptive behaviour: a) estimated walking distance from parking spot to the final destination (walking time), b) parking cost and c) estimated parking search time. Based on survey results and calculated weights $\left(w_{i}, k_{s}, k_{p}\right)$ we have scaled problem to optimisation of parking search time with free parking spot as decision variable. Three choices of adaptive behaviour were analysed: wait for a free space (scenario 1), go to the next parking spot (scenario 2) or give up parking search in these zones if system feedback informs driver about no free parking spot (scenario 2).

Using experimental model simulation with parking system feedback, results (see Fig. 9) show that after 2 hours $2.5 \%$ of total time was spent on parking search. Also, around $30 \%$ of drivers were informed about no parking spot vacancy before entering city urban area resulting with less than $2 \%$ of drivers using no regulated parking places. Also, it is important to mention that after period of 2 hours only 12 vehicles has remained on road searching for free parking spot. 


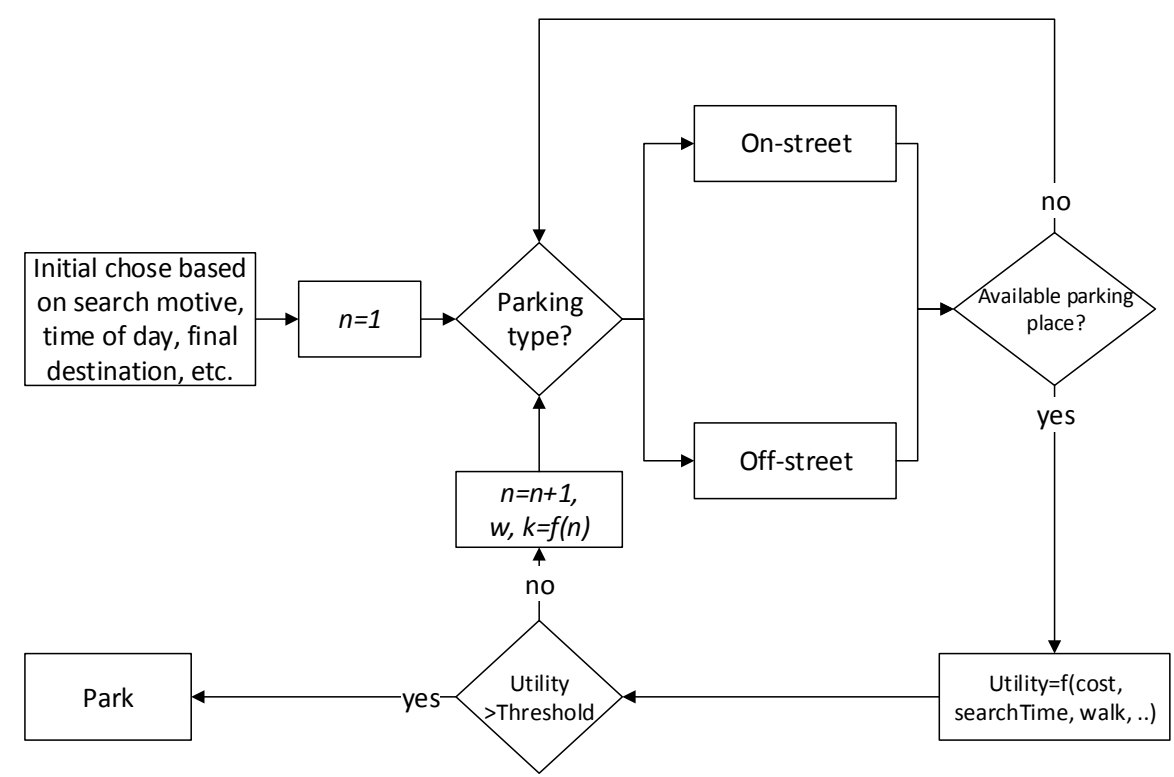

Figure 8: Schematic representation of the parking decision making strategy.

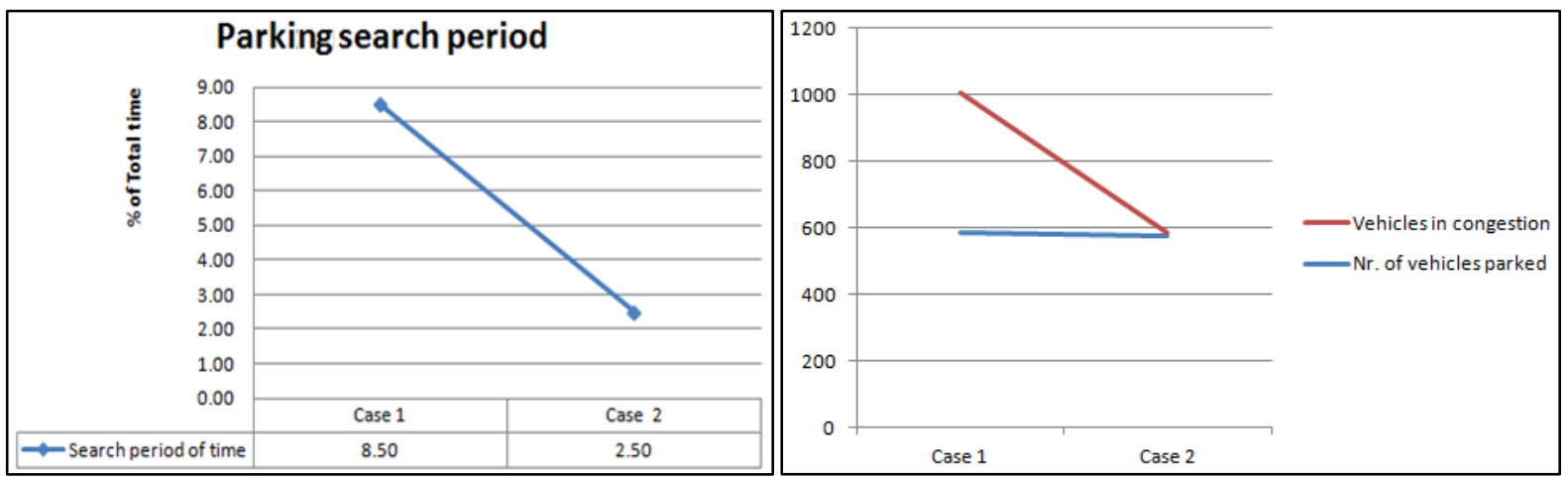

Figure 9: Comparison of served vehicles and vehicles on roads after 2 hours.

\section{CONCLUSION \& FUTURE WORK}

This paper is only the first step in solving parking search problem. We present the methodology and initial simulation taking into account identified related open data and drivers' preferences (walking distance). Because of that, we firstly analyse all possible open data sources as well as all related researches and solutions grouping them based on data sources. Utility function that maximizes the expected utility was also described.

We have used, through all research, real data collected by demographic survey conducted in city of Novi Sad. Rockwell Automation Arena ${ }^{\circledR}$ simulation tool was used for model simulation. Our simulation model shows that parking search time can be reduced by $70 \%$ using parking system feedback. The information timely transferred to the driver proves to be very valuable resource for decision-making and avoiding traffic jams.

Despite the fact that utility function is just about the drivers' convenience, our final focus is minimizing not only drivers but also public cost. The model can be improved by including traffic model, rules and conditions. Then, drivers' behaviour will be further analysed and his walking, price, etc. tolerance calibrated with every search iteration (see Fig. 8). Also some other optimization methods [23] and optimization of travel speed will be taken into consideration since it can decrease average delays up to $70 \%$ [24]. The analysed results are encouraging further researches of parking search problems. 


\section{ACKNOWLEDGEMENT}

This research is part of Project number III43002 which is financially supported by Ministry of Education, Science and Technological Development of the Republic of Serbia.

\section{REFERENCES}

[1] Shoup, D. (2005). The high cost of free parking, $18^{\text {th }}$ edition, Planners Press, American Planning Association, Chicago

[2] IBM Global Parking Survey. Drivers Share Worldwide Parking Woes, IBM, Armonk, NY, USA, from https://www-03.ibm.com/press/us/en/pressrelease/35515.wss, accessed on 17-12-2015

[3] Leibling, J. The Royal Automobile Club Foundation for Motoring. Spaced out perspectives on parking policy, from http://www.racfoundation.org/assets/rac_foundation/content/downloadables /spaced_out-bates_leibling-jul12.pdf, accessed on 14-11-2015

[4] Djuric, N.; Grbovic, M.; Vucetic, S. (2016). ParkAssistant: An algorithm for guiding a car to a parking spot, Proceedings of the $95^{\text {th }}$ Annual Meeting of the Transportation Research Board, 12 pages

[5] Feng, X.; Gan, T.; Wang, X.; Sun, Q.; Ma, F. (2015). Feedback analysis of interaction between urban densities and travel mode split, International Journal of Simulation Modelling, Vol. 14, No. 2, 349-358, doi:10.2507/IJSIMM14(2)CO9

[6] Conceição, H.; Damas, L.; Ferreira, M.; Barros, J. (2008). Large-scale simulation of V2V environments, Proceedings of the 2008 ACM symposium on Applied computing, 28-33

[7] Jevdjenic, A. - Institute for Urban Planning, Novi Sad (2009). Traffic study of the City of Novi Sad with the traffic regulation dynamics - NOSTRAM, from http://www.nsurbanizam.rs/ sites/default/files/1770\%20Saobracajna\%20studija-NOSTRAM-.pdf, accessed on 19-12-2015 (in Serbian)

[8] Public Company "Parking Service", Novi Sad (2005). Study of the parking characteristics in the central area of Novi Sad, available upon request (in Serbian)

[9] Yeh, H.-T.; Chen, B.-C.; Wang, B.-X. (2016). A city parking integration system combined with cloud computing technologies and smart mobile devices, EURASIA Journal of Mathematics, Science \& Technology Education, Vol. 12, No. 5, 1231-1242, doi:10.12973/eurasia.2016.1509a

[10] Kopecký, J.; Domingue, J. (2012). ParkJam: crowdsourcing parking availability information with linked data (Demo), Proceedings of the $9^{\text {th }}$ Extended Semantic Web Conference (ESWC 2012), 5 pages

[11] Villalobos, J.; Kifle, B.; Riley, D.; Quevedo-Torrero, J. U. (2015). Crowdsourcing automobile parking availability sensing using mobile phones, Proceedings of the $14^{\text {th }}$ Annual UW System Symposium for Undergraduate Research \& Creative Activity, Poster II-103, 8 pages

[12] ParkTAG GmbH, Berlin. PARK Tag, from http://parktag.mobi/about-us/, accessed on 05-012016

[13] Nandugudi, A.; Ki, T.; Nuessle, C.; Challen, G. (2014). Pocketparker: Pocketsourcing parking lot availability, Proceedings of the 2014 ACM International Joint Conference on Pervasive and Ubiquitous Computing, 963-973

[14] Timpner, J.; Schurmann, D.; Wolf, L. (2016). Trustworthy parking communities: helping your neighbor to find a space, IEEE Transactions on Dependable and Secure Computing, Vol. 13, No.1, 120-132, doi:10.1109/TDSC.2015.2427838

[15] Caicedo, F.; Blazques, C.; Miranda, P. (2012). Prediction of parking space availability in real time, Expert Systems with Applications, Vol. 39, No. 8, 7281-7290, doi:10.1016/j.eswa. 2012.01.091

[16] Nedap N.V. Nedap identification systems, from http://www.nedapidentification.com, accessed on 20-11-2015

[17] SFMTA, Municipal Transportation Agency. SFpark, from http://www.sfpark.org, accessed 2009-2015

[18] Vlahogianni, E. I.; Kepaptsoglou, K.; Tsetsos, V.; Karlaftis, M. G. (2016). A real-time parking prediction system for smart cities, Journal of Intelligent Transportation Systems, Vol. 20, No. 2, 192-204, doi: $\underline{10.1080 / 15472450.2015 .1037955}$ 
[19] Mathur, S.; Kaul, S.; Gruteser, M.; Trappe, W. (2009). ParkNet: a mobile sensor network for harvesting real time vehicular parking information, Proceedings of the 2009 MobiHoc S 3 Workshop on MobiHoc S 3, 25-28

[20] Hampshire, R. C.; Jordon, D.; Akinbola, O.; Richardson, K.; Weinberger, R.; Millard-Ball, A.; Karlin-Resnik, J. (2016). Analysis of parking search behavior with video from naturalistic driving, Transportation Research Record: Journal of the Transportation Research Board, Vol. 2543, 152-158, doi: $10.3141 / 2543-18$

[21] Cheng, P.; Zhou, G.; Zheng, Z. (2009). Detecting and counting vehicles from small low-cost UAV images, ASPRS 2009 Annual Conference Proceedings, 7 pages

[22] Wang, X.; Schulzrinne, H. (2006). Pricing network resources for adaptive applications, IEEE/ACM Transactions on Networking, Vol. 14, No. 3, 506-519, doi:10.1109/TNET.2006. $\underline{872574}$

[23] Tang, M.; Gong, D.; Liu, S.; Zhang, H. (2016). Applying multi-phase particle swarm optimization to solve bulk cargo port scheduling problem, Advances in Production Engineering \& Management, Vol. 11, No. 4, 299-310, doi:10.14743/apem2016.4.228

[24] Wu, W.; Li, P. K.; Zhang, Y. (2015). Modelling and simulation of vehicle speed guidance in connected vehicle environment, International Journal of Simulation Modelling, Vol. 14, No. 1, 145-157, doi:10.2507/IJSIMM14(1)CO3 